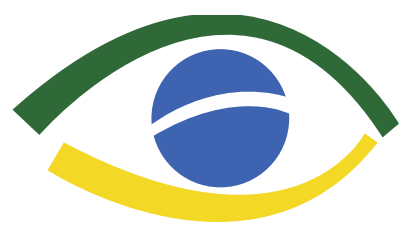

\section{Observatório da Jurisoliçãc Constitucional}

Observatório da Jurisdição Constitucional. Ano 7, no. 1, jan./jun. 2014. ISSN 1982-4564.

\title{
Poder Executivo Forte
}

Rodrigo de Bittencourt Mudrovitsch ${ }^{*}$

Resumo: $O$ artigo analisa as principais características institucionais de Poderes Executivos fortes. Duas conclusões são apontadas: (i) um Poder Executivo forte não é o inventado por ocasião do desenvolvimento da doutrina da separação de poderes e nem foi praticado no despertar das revoluções inglesa, francesa e norte-americana; e (ii) um Poder Executivo forte preferencialmente é eleito diretamente por sufrágio universal e deve possuir amplo poder de agenda. Será mencionado o exemplo da experiência brasileira pós-1988.

Palavras-chave: Poder Executivo; Separação de poderes; Poder de agenda; Eleição direta.
Abstract: This Essay analyses the main institutional features of strong Executive Powers. Two conclusions are presented: (i) a strong Executive Power was not invented by the doctrine of separation of powers and was not practiced at the awakening of the liberal revolutions of France, England and the United States; and (ii) a strong Executive Power is generally elected by direct and universal suffrage and must have a broad agenda power. The Brazilian post-1988 example will be mentioned.

Keywords: Executive power; Separation of powers; Agenda power; Direct suffrage.

* Advogado-sócio do escritório Mudrovitsch Advogados e Doutorando em Direito Constitucional pelo Departamento de Direito do Estado da USP. É Mestre em Direito, Estado e Constituição pela UnB. Possui graduação em Direito pela UnB. Atualmente, é Professor do IDP, da EDB e Professor voluntário da UnB na área de Direito Público. 


\section{Objeto do ensaio}

O Executivo representa o Poder mais forte nas sociedades atuais, independentemente do regime político aplicado. Contudo, conquanto a relevância do Poder Executivo nos dias de hoje seja completamente diferente daquela imaginada à época da criação da doutrina tradicional da separação de poderes, o impacto dessa evolução com relação à estruturação do Poder Executivo em si é pouco debatida atualmente no âmbito das ciências sociais.

Assim, a pergunta que pautará o presente ensaio é: o que é um Poder Executivo forte? As seguintes respostas serão apresentadas:

(i) Um Poder Executivo forte não é o inventado por ocasião do desenvolvimento da doutrina da separação de poderes e nem foi praticado no despertar das revoluções inglesa, francesa e norte-americana; e

(ii) Um Poder Executivo forte preferencialmente é eleito diretamente por sufrágio universal e deve possuir amplo poder de agenda, exatamente como ocorre na experiência brasileira pós-1988.

O pressuposto de validade das respostas acima apresentadas é a existência de um regime democrático adequadamente consolidado. O conceito de democracia utilizado no ensaio é minimalista, no sentido de que "democracias são regimes políticos nos quais os principais postos de governo são ocupados como resultado da disputa eleitoral aberta e regular" (Przeworski, Limongi, 1994).

Serão desconsideradas as experiências constitucionais brasileiras anteriores a 1945. Isso porque, conforme apontado por Fernando Limongi,

A eleição de 1945 marca o início da primeira experiência democrática do Brasil. Eleição, por si só, não é condição suficiente para qualificar o regime nascente como democrático. Eleições não eram novidade na história política do Brasil, afinal, direta ou indiretamente, governos foram eleitos por mais de cem anos, de 1822 a 1930. Ainda assim, há uma ruptura em 1945; eleições passam a ser competitivas. Há uma mudança na natureza do processo eleitoral; o governo perde o controle que sempre tivera sobre o processo eleitoral. (2012)

Pelo mesmo motivo, também serão desprezadas as experiências constitucionais brasileiras compreendidas entre 1964-87. Embora seja impossível afirmar que o regime político praticado no país durante esse período tenha sido uno, uma vez que, na verdade, o Brasil vivenciou regimes militares de diferentes intensidades e estruturados em distintas 
institucionalidades, o propósito da escolha do período posterior a 1988, em comparação a 1945-64, é facilitar a contextualização do debate.

\section{Metamorfoses institucionais}

O melhor ponto de partida para explicar a naturalidade da metamorfose teórica e prática sofrida pelo Poder Executivo entre os séculos XVIII e XXI é a comprovação de que semelhante fenômeno também ocorreu com relação à própria democracia representativa.

Na obra "The Principles of Representative Government", Bernard Manin deixa claro que "o que hoje se entende por democracia representativa tem as suas origens em sistemas de instituições (estabelecidos no despertar das revoluções inglesa, americana e francesa) que, de maneira alguma, foram inicialmente concebidos como formas de democracia ou de governo pelo povo" (2002:1). O autor retira essa conclusão não apenas dos modelos institucionais ou consuetudinários de distinção aristocrática entre eleitos e eleitores existentes na França, na Inglaterra e nos Estados Unidos no final do século XVIII (2002:94-131), mas também dos próprios ensinamentos de teóricos clássicos do governo representativo, como Rosseau, Madison e Siéyès. Nesse sentido, comprovou que o fundamento da representação, tal como foi inicialmente concebida nesses países, era justamente selecionar os mais afortunados como governantes. Segundo Manin, foram necessárias metamorfoses inesperadas para que o governo representativo se aproximasse da democracia atual, tais como o surgimento do sufrágio universal e de partidos políticos (2002:194).

Especificamente em relação aos partidos políticos, após apontar autores que viam esse desenvolvimento das democracias como evidência de crise da representatividade política, Manin defendeu exatamente o oposto, por entender que "os partidos aproximaram os representantes das suas comunidades, fazendo com que fosse possivel a indicação de candidatos cuja posição social, estilo de vida e preocupações fossem próximos aos daqueles pertencentes às camadas mais pobres da sociedade" (2002:195-196).

É curioso notar que a mesma tese defendida por Manin com relação à democracia representativa foi apresentada por Richard Hofstadter com relação aos próprios partidos políticos. A tese que estrutura a obra "The Idea of a Party System - The Rise of Legitimate Opposition in the United States, 1780-1840" foi justamente a comprovação, a partir da experiência norte-americana, de que "primeiro os partidos políticos tiveram que ser criados; 
depois começaram a ganhar aceitação teórica" (1997:39). Hofstadter ilustrou a sua tese, nesse sentido, com as três concepções teóricas sobre partidos políticos existentes no final do século XVIII. As duas majoritárias eram claramente negativistas. A última, única favorável, era praticamente ignorada à época.

A primeira concepção apresentada por Hofstadter é a ortodoxa, que na Inglaterra vinha especialmente de St. John Henry, Visconde de Bolingbroke, e nos Estados Unidos de Alexander Hamilton. A essência dessa visão era negativa, no sentido de que os partidos políticos seriam equivalentes a facções e que, portanto, deveriam ser abolidos, ainda que, para que isso pudesse ocorrer, paradoxalmente fosse necessária a criação de um partido único, representante de uma suposta unificação nacional.

A segunda concepção é a intermediária, que na Inglaterra vinha especialmente de David Hume e nos Estados Unidos de James Madison. A essência dessa visão não era totalmente abolicionista. O pensamento era o de que, ainda que os partidos fossem essencialmente ruins, a existência deles não podia ser evitada em Estados livres. Desse modo, os partidos políticos deveriam ser vistos como o preço a se pagar pela liberdade política. Nesse sentido, no Artigo Federalista n. 10, Madison defendeu que "as causas do surgimento das facções são decorrentes da própria natureza humana”. Por isso, segundo David Hume a principal influência teórica de Madison -, "abolir todas as distinções entre os partidos não será possível, e talvez nem desejado em governos livres". A solução, portanto, para Hume, seria abolir apenas os "partidos perigosos", "aqueles que possuíssem visões opostas em relação a questões essenciais do governo", ou seja, aqueles cujas ideologias pudessem levar a guerras civis ou revoluções. O caminho, nesse sentido, era confinar as divergências entre os partidos àquelas em relação àqueles em que houvesse possibilidade de obtenção de acordos intermediários. Essa visão, que Hofstadter chama de "teoria qualificada anti-partidária", era dominante do pensamento político norte-americano do final do século XVIII (1997:17-28).

A terceira concepção apresentada por Hofstadter é a favorável. Na Inglaterra, vinha essencialmente de Edmund Burke. Nos Estados Unidos não possuía adeptos. Burke via os partidos políticos não apenas como inevitáveis, mas como essencialmente necessários e, na maioria das vezes, produtores de resultados favoráveis à sociedade. Segundo Burke, os partidos políticos poderiam ser positivos ou negativos, mas, por si sós, seriam "o único caminho para prevenir grandes estragos". Para Hofstadter, independentemente da vulnerabilidade de Burke em relação aos interesses políticos que subjaziam as suas 
conclusões teóricas, a sua ideia central de que os partidos políticos poderiam ter feições positivas foi de extrema importância para a ciência política. Contudo, segundo Hofstadter, não houve influência direta do pensamento de Burke nos políticos americanos do final do século XVIII. Isso porque, no auge de Burke, os norte-americanos ainda não estavam envolvidos com discussões sobre a criação ou não de partidos políticos. Duas décadas depois, quando passaram a se envolver com o assunto, Burke já não gozava de tanta influência, e, além disso, os Federalistas, que estavam no poder, possuíam posição mais do que sedimentada em sentido contrário à existência de partidos políticos. Hofstadter identifica apenas manifestações de autores e políticos norte-americanos obscuros no século XVIII em defesa de partidos políticos. Uma exceção apontada por Hofstadter é a manifestação de Hamilton, no Artigo Federalista n. 70, no sentido de que: "No Poder Legislativo, decisões de prontidão são piores na maioria das vezes. As diferenças de opinião, as discordâncias entre partidos políticos dentro do Poder Legislativo, ainda que possam obstruir programas políticos saudáveis, geralmente promovem a deliberação e a vigilância, servindo para limitar excessos da maioria". Trata-se, contudo, de declaração dúbia, já que o próprio Hamilton, em seguida, afirmou que oposições ao resultado dos trabalhos legislativos deveriam ser punidas (1997: 29-33).

É interessante notar, nesse sentido, que a única posição teórica favorável à criação de partidos políticos foi exatamente aquela que não foi levada em consideração nos Estados Unidos durante o período em que efetivamente surgiu uma oposição legítima amparada em bases partidárias.

Diferentemente do que se poderia imaginar, os exemplos acima citados de metamorfoses institucionais não são excepcionais. A rigor, raciocínios semelhantes podem ser empregados em todas as instituições humanas, justamente pelo fato de que, conforme bem reconhecido por Roberto Mangabeira Unger,

O que nós temos ao redor de nós não é um sistema fundado de acordo com um plano racional. Não é uma máquina construída de acordo com um projeto em relação ao qual tivemos acesso apenas por providência divina. É apenas um arranjo institucional e ideológico, uma parcial e temporária interrupção da disputa, um compromisso não apenas entre grupos de interesse mas também entre grupos de interesse e possibilidades coletivas, seguido de uma série de pequenas crises e ajustes menores, e repleto de contradições escondidas e oportunidades transformadoras (2004:19-20). 
No âmbito da jurisdição constitucional, por exemplo, o referido pensamento é aplicado por (i) Jürgen Habermas, para reconhecer que, nas democracias, a própria existência de "tribunais constitucionais não é autoevidente" (2003:298); e (ii) Mark Tushnet, para defender que o instituto do judicial review nada mais é do que um "grande experimento" humano (1999:154).

Seria surpreendente, portanto, que o exercício de Manin e Hofstadter gerasse conclusões distintas quando aplicado ao Poder Executivo. É, por conseguinte, quase intuitivo imaginar que o significado prático do Poder Executivo nos dias atuais se tornou radicalmente distinto daquele inicialmente visualizado pelos teóricos clássicos da separação de poderes, assim como da realidade vivenciada à época. A rigor, a dominação que hoje se verifica do Poder Executivo sobre o Poder Legislativo, ao menos no Brasil (Limongi, Figueiredo, 1995), era invertida na prática e na teoria dominantes do final do século XVIII.

É ilustrativa, a respeito da prática executiva da época, a seguinte descrição realizada por Willi Paul Adams no livro "The First American Constitutions":

É sabido que os governos estaduais das primeiras constituições (norte-americanas) eram caracterizados por um forte legislativo e por um executivo fraco; a explicação convencional para isso é que, no passado, governadores (...) eram vistos como inimigos e que era natural para os republicanos, em 1776, querer fugir de executivos fortes. (2001:269)

A teoria política dominante partilhava visão semelhante. Montesquieu, na obra " $O$ Espírito das Leis", expressamente subordinou o Poder Executivo ao Poder Legislativo, chegando ao ponto de afirmar que, diferentemente do controle do primeiro sobre o segundo, que deveria sempre ser institucionalizado a partir de alguma espécie de poder de veto ou de limitação das iniciativas legislativas, o controle do segundo sobre o primeiro seria mais simples, pois a execução se caracterizaria, per se, como espécie de atividade limitada por natureza. Montesquieu despreza, nesse sentido, a própria necessidade de matérias com iniciativa legislativa reservada ao Poder Executivo.

As seguintes passagens da obra em questão são bastante elucidativas a respeito da visão do autor sobre a preponderância do Legislativo sobre o Executivo:

Se o poder executivo não tiver o direito de limitar as iniciativas do corpo legislativo, este será despótico; pois, como ele poderá outorgar-se todo o poder que puder imaginar, anulará os outros poderes. Mas não é preciso que o poder legislativo tenha reciprocamente a faculdade de limitar o executivo. Pois, sendo a 
execução limitada por natureza, é inútil limitá-la; além do que o poder executivo exerce-se sempre sobre coisas momentâneas. (...) se num Estado livre, o poder legislativo não deve frear o poder executivo, tem o direito e deve ter a faculdade de examinar de que maneira as leis que criou foram executadas. (...) Como o poder executivo só faz parte do legislativo com sua faculdade de impedir, não poderia participar do debate das questões. Não é nem mesmo necessário que proponha, porque, podendo sempre desaprovar as resoluções, pode rejeitar as decisões das propostas que não gostaria que tivessem sido feitas. (2005:173-177).

Fica claro, portanto, que (i) Poder Executivo forte era exatamente o que não se imaginava ou praticava no final do século XVIII; e (ii) semelhantemente ao que ocorreu com grande parte do repertório de instituições políticas criadas ou implantadas após as revoluções inglesa, americana e francesa, não é surpreendente verificar que a prática do século XXI é radicalmente distinta, com Poderes Executivos bastante robustecidos e ascendentes sobre os Poderes Legislativos. A próxima parte do ensaio será dedicada a apresentar dois fatores institucionais que, via de regra, sustentam essa viragem.

\section{Robustecimento do Poder Executivo: eleições diretas e poder de agenda}

A eleição direta para o chefe do Poder Executivo é vista atualmente como inerente aos regimes democráticos. No Brasil, aliás, as eleições presidenciais diretas foram a grande política constitucional que fundamentou o acordo das oposições no momento da transição democrática pré-Constituinte. Existe, até os dias atuais, certa crença consolidada na teoria social de que o ressurgimento da sociedade civil no momento da campanha pelas "Diretas$J a ̂ "$ teria sido determinante para a inédita permeabilidade do processo constituinte brasileiro de 1987-88 (Bertoncello, Hagopian). Ainda que seja claramente perceptível o exagero ideológico que embasa essas visões, é inequívoco que a "crença mítica nas eleições presidenciais" (Campello de Souza, 1987) permanece fortemente enraizada no imaginário democrático brasileiro atual. O motivo é simples: consolidou-se a percepção de que, no que diz respeito ao papel dos eleitores, quanto mais espaço na agenda pública, melhor.

Há consequências, contudo, da eleição direta do chefe do Poder Executivo que são pouco debatidas. Em interessante artigo intitulado "Doing Away With Presidencial Elections", publicado em linguagem simplificada na internet, Pierre Brunet e Arnaud Le Pillouer afirmam que a eleição direta para o ocupante do posto máximo do Poder Executivo representaria um 
dos principais motivos para a criação de "hiper-presidentes ou oni-presidentes". Na visão dos autores, "a eleição do Presidente por meio do sufrágio universal direto está prejudicando a saúde política da França, por robustecer a ideia de que a democracia pode ser reduzida à vontade de um indivíduo". Com isso, as eleições presidenciais acabariam ofuscando outros certames eleitorais e afastando o interesse e a confiança da população nas atividades das demais instituições políticas.

Ademais, segundo Brunet e Pillouer, as eleições presidenciais criariam uma espécie de hierarquia representacional do chefe do Poder Executivo sobre os partidos políticos e os integrantes dos demais Poderes, a partir da ficção de que o primeiro seria o representante da vontade de toda uma nação, ao passo que os demais representariam apenas os seus respectivos eleitorados regionalizados ou segmentados ideologicamente. $O$ resultado seria uma legitimação democrática mais profunda do representante do Poder Executivo que contribuiria para o "desbalanceamento das instituições políticas" (2011), com pouquíssimo espaço para que os representantes do Poder Legislativo efetivamente pudessem controlar a atividade do chefe do Estado. Brunet e Pillouer são categóricos, quando analisam o que chamam de fator desestabilizador da separação de Poderes em favor do Executivo, ao afirmar que a solução não passa pelo incremento de poderes institucionais de accountability horizontal no Legislativo ou no Judiciário, mas pela supressão do sufrágio universal direto para escolha do representante máximo do Executivo.

Portanto, a partir dessa análise, é difícil imaginar que uma primeira resposta parcial à pergunta inicial do ensaio - "O que é um Poder Executivo Forte?" - não seja: aquele eleito diretamente por sufrágio universal. O exame mais detalhado dos arranjos institucionais de democracias presidencialistas, contudo, faz com que seja necessário acrescentar outro arranjo institucional à resposta: o poder de agenda. Isso porque, diferentemente do que sugerem Brunet e Pillouer, o poder de agenda chega inclusive a ser preponderante à própria eleição direta como mecanismo de fortalecimento do Poder Executivo. A radical mudança institucional praticada no Brasil pela Constituição Federal de 1988 em relação ao período democrático de 1945-64 é o melhor exemplo que pode ser apresentado.

É consolidado hoje o entendimento de que, no Brasil, "o presidente, que teve seu poder institucional reforçado pela Constituição de 1988, detém monopólio sobre iniciativa legislativa, o que aproxima o sistema brasileiro das democracias parlamentaristas europeias" (Limongi, 2006:17). Com efeito, o amplo poder decisório conferido pela 
Constituição de 1988 ao Poder Executivo modificou sobremaneira a sua relação com o Poder Legislativo. Diferentemente do ocorrido com relação ao texto constitucional brasileiro de 1946, havia certo consenso na Assembleia Nacional Constituinte de 1987-88 no sentido de que:

(...) o sucesso da democracia dependia da capacidade governo dar respostas efetivas e rápidas às crescentes demandas postas aos governos por sociedades modernas e complexas. A modernização institucional foi o leitmotiv sobre a qual se deu a definição das relações entre o Executivo e o Legislativo. O processo decisório precisava ser dotado de eficiência. Protelar decisões seria a forma de alimentar crises, de não dar as respostas demandadas pela sociedade. Em sendo assim, o principal obstáculo a ser transposto era o conservadorismo e a morosidade característicos do Poder Legislativo. Para tanto, era necessário fortalecer o Poder Executivo evitando que este pudesse ser paralisado pela inação do Legislativo. Mais do que isto, era preciso dotar o Executivo de "vias de escape" sempre que uma possível divergência entre os poderes pudesse redundar em confronto ou inação. (Limongi, 2008:3).

Nesse sentido, defende Limongi que o "entulho autoritário" (Campello de Souza, 1987) existente no texto constitucional de 1967/69 não foi totalmente removido pela Assembleia Nacional Constituinte de 1987-88, ao menos no que diz respeito ao Poder Executivo. No tocante a esse tema, o Brasil optou conscientemente por não retomar as bases institucionais de 1946, mantendo instituições centralizadoras do regime militar, como o poder de decreto do Executivo e o seu controle sobre a elaboração e a execução do orçamento (2008:4). Para o autor,

A Carta de 1988, portanto, não representa um retorno a ordem legal criada pelo texto constitucional de 1946. Muito menos teria fortalecido o Poder Legislativo às expensas do Poder Executivo. Tampouco representa uma pura e simples rejeição da 'engenharia institucional' do período autoritário. Por qualquer parâmetro que se use, o Poder Executivo não pode ser qualificado de fraco. As bases deste poder presidencial são institucionais e consagradas no texto constitucional e de forma alguma se resumem às suas relações diretas com o eleitorado.

No texto "As bases institucionais do presidencialismo de coalizão" (1995), Limongi e Figueiredo afirmam cruamente que, por ocasião das escolhas institucionais dos integrantes da Assembleia Nacional Constituinte de 1987-88, grande parte delas radicalmente antagônicas às opções de 1946, o Poder Executivo se transformou no principal legislador, de fato e de direito, do Brasil. A preocupação dos constituintes de 1946 com a limitação dos excessos do 
sistema ditatorial em tese extinto com a renúncia de Getúlio Vargas não se repetiu na Assembleia Nacional Constituinte de 1987-88. A experiência militar, nesse sentido, foi mais influente em 1987-88 do que a herança do primeiro período democrático brasileiro.

O resultado foi a previsão constitucional de um Poder Executivo (i) eleito diretamente pelo voto universal, (ii) com iniciativas legislativas exclusivas sobre projetos de lei administrativos, orçamentárias e sobre matérias tributários; (iii) com iniciativa para projetos de emenda constitucional; (iv) com prerrogativa para editar medidas provisórias; e (v) com possibilidade de editar leis sob requerimento de delegação do Congresso, solicitar urgência nos projetos de lei e impor restrições a emendas orçamentárias do Congresso (Limongi, 1998). A tese de Limongi é que, nesse cenário, se tornou pouco relevante a opção por parlamentarismo ou presidencialismo. O ponto institucional que efetivamente importou para a criação de um Poder Executivo forte foi o controle da agenda decisória legislativa, não o método de eleição. Em termos de poder decisório, o texto constitucional de 1988 foi extremamente generoso com o Poder Executivo, fazendo com que o índice de dominância deste sobre o Poder Legislativo aumentasse de 34,5\% no governo do Presidente Gaspar Dutra para $89,88 \%$ no primeiro mandato do Presidente Lula (Limongi, 1998). O resultado da mudança foi assim sintetizado por Limongi:

A interpretação dos dados apresentados é bastante direta: pelo texto constitucional em vigor, o Executivo controla a agenda legislativa do país. Cabe à Presidência da República propor alterações do status quo. Do ponto de vista legal, o que muda no país, muda por iniciativa do Executivo. A base do poder presidencial é, portanto, institucional, dependendo muito pouco do tamanho da bancada do seu partido e das suas qualidades como negociador. Não fosse assim e as taxas de sucesso e dominância verificados não seriam estáveis. (2008:22).

É evidente que o domínio da agenda decisória não deu ao chefe do Poder Executivo brasileiro poderes ilimitados sobre o Poder Legislativo. Permanece necessária a obtenção de apoio da maioria dos legisladores, mesmo com relação às medidas provisórias. Ainda assim, há pouco espaço para a existência de um Poder Legislativo rebelde no cenário brasileiro pós1988, porque (i) "os trabalhos legislativos no Brasil são altamente centralizados e se encontram ancorados na ação dos partidos"; (ii) "o Executivo, por controlar o acesso à patronagem, dispõe de recursos para impor disciplina aos membros da coalizão que o apoia"; e (iii) "parlamentares não encontram arcabouço institucional próprio para perseguir interesses particularistas" (Limongi, Figueiredo, 1995:84-86). 


\section{Referências Bibliográficas}

ADAMS, Will P.: The First American Revolutions - Republican Ideology and the Making of The State Constitution in the Revolutionary Era, Lanham, "A Madison House Book", Rowman \& Littefield Publishers, 2001.

BRUNET, Pierre; PILLOUER, Arnaud Le. Doing Away With Presidential Elections. Disponível em: http://www.booksandideas.net/doing-away-with-presidential.html.

FIGUEIREDO, Argelina; LIMONGI, Fernando $\cdot \underline{\text { As Bases Institucionais do }}$ Presidencialismo de Coalizão. Lua Nova. Revista de Cultura e Política, São Paulo, v. 44, p 81-106, 1998.

HABERMAS, Jürgen. Direito e democracia: entre facticidade e validade. Volume I, $2^{\mathrm{a}}$ Ed., Tradução: Flávio Beno Siebeneichler, Rio de Janeiro: Tempo Brasileiro, 2003a.

HOFSTADTER, Richard. The idea of a party system: the rise of legitimate opposition in the United States, 1780-1840. Los Angeles: University of California Press, 1997.

LIMONGI, Fernando; PRZEWORSKI, Adam. Democracia e Desenvolvimento na América do Sul, 1946-1988. Revista Brasileira de Ciências Sociais, n. 24, p. 31-48, 1994.

LIMONGI, Fernando. O Poder Executivo na Constituição de 1988. Disponível em:

LIMONGI, Fernando. A Democracia no Brasil. Presidencialismo, coalizão partidária e processo decisório. Novos Estudos. CEBRAP, v. 76, p 17-41, 2006.

LIMONGI, Fernando. Eleições e democracia no Brasil: Victor Nunes Leal e a transição de 1945. Dados (Rio de Janeiro. Impresso), v. 55, p. 37-69, 2012.

MANIN, Bernard. The principles of representative government. New York: Cambridge University Press, 1997.

MONTESQUIEU, Charles de Secondat, Baron de. O Espírito das Leis. $3^{\text {a }}$ Ed., São Paulo: Martins Fontes, 2005.

TUSHNET, Mark. Taking the Constitution Away from the Courts, Princeton: Princeton University Press, 1999.

UNGER, Roberto Mangabeira. $O$ direito e o futuro da democracia. $1^{\text {a }}$ Ed., Rio de Janeiro: Boitempo, 2004.

Artigo recebido em 17 de março de 2014. Artigo aprovado para publicação em 27 de maio de 2014.

DOI: $10.11117 / 1982-4564.07 .04$ 